\title{
Demographic and clinical characteristics in asymptomatic health workers with positive SARS-CoV-2 test, Hospital General de México "Dr. Eduardo Liceaga"
}

\author{
Rafael M. Navarro-Meneses, Fátima del R. Molina-Carrasco, Carlos Santamaría-Saad*, \\ Jorge F. Moises-Hernández, and Guadalupe M. L. Guerrero-Avendaño \\ Department of Otorhinolaryngology and Head and Neck Surgery, Hospital General de México "Dr Eduardo Liceaga”, Mexico City, México
}

\begin{abstract}
Objective: The objective of the study was to describe the demographic and clinical characteristics found in personnel screened during the severe acute respiratory syndrome coronavirus 2 (SARS-CoV-2) pandemic. Materials and methods: $\mathrm{Na-}$ sal and oropharyngeal swab samples were collected in the period between May 11 and May 26, 2020, from 496 people. They were followed up by means of a questionnaire at 0, 7, and 14 days. Results: 449 people answered the surveys (73 excluded); age range: $21-63$ years, mean of 39.4 years. About $77 \%$ had contact with patients with coronavirus infection, (32\% had an exposure time of $<8 \mathrm{~h}$ a week, 24\% 8-16 $\mathrm{h}$ a week and 20\% more than $16 \mathrm{~h}$ a week). The most frequent comorbidity in the population was obesity (13.8\%), followed by asthma (8\%) and DM2 (1\%). The most common symptom was headache (34\%), followed by nasal obstruction (25\%) and odynophagia in third place (22\%); $16 \%$ presented alterations in the perception of odors. Among the surveyed personnel, 17 (4.5\%) tested positive for SARS-COV2 by means of reverse transcription polymerase chain reaction. Conclusions: In line with this pandemic, a screening protocol was started for asymptomatic health-care personnel for the recognition of infections caused by this virus to establish barriers that will prevent the spread and provide the basis for the standardization of this practice and the protection of healthcare personnel.
\end{abstract}

Key words: COVID-19. Human Coronavirus. SARS-CoV-2. Screening.

\section{Introduction}

At the end of 2019, there was a significant increase in cases associated with severe acute respiratory syndrome, previously unknown, in the city of Wuhan, China. In January 2020, severe acute respiratory syndrome coronavirus 2 (SARS-CoV-2) was identified as the causative agent ${ }^{1,2}$, which spread globally and was declared a pandemic in March 2020 by the World Health Organization $^{3}$. The clinical features and risk factors for contracting this disease are highly variable, which means that the clinical spectrum can range from asymptomatic or paucisymptomatic forms, with little or no expressive symptomatology, to clinical conditions characterized by severe respiratory failure, sepsis, septic shock and multiple organ dysfunction syndromes ${ }^{3}$.

The standard for detection of SARS-CoV-2 is real-time reverse transcriptase polymerase chain reaction (RT-PCR) assays collected from nasal and oropharyngeal swab samples, which means that the viral load at these sites must be high ${ }^{4}$. It is widely
Correspondence:

*Carlos Santamaría-Saad

E-mail: carlos.santamaria93@gmail.com
Date of reception: 09-07-2020

Date of acceptance: 13-10-2020 DOI: $10.24875 / H G M X .20000074$
Available online: 19-04-2021

Rev Med Hosp Gen Mex. 2021;84(2):59-63 www.hospitalgeneral.mx 0185-1063/@ 2020 Sociedad Médica del Hospital General de Mexico. Published by Permanyer. This is an open access article under the CC BYNC-ND license (http://creativecommons.org/licenses/by-nc-nd/4.0/). 
recognized that screening is an imperfect barrier to spread, due to the absence of detectable symptoms during the incubation period; variation in severity and detectability of symptoms once the disease begins to progress; and imperfect performance of screening equipment or personnel ${ }^{5}$.

However, detection of symptoms has become and remained a ubiquitous tool in the effort to contain the local spread of COVID-195. In March, some European otolaryngologists observed that SARS-CoV-2 infected patients presented with severe olfactory and gustatory dysfunction without rhinorrhea, nasal obstruction, or other symptoms such as fever or cough, so COVID-19 was not suspected in some of these patients ${ }^{6}$.

It is crucial to identify, isolate, and follow-up asymptomatic carriers and staff with mild symptomatology to contain the spread of the virus. Therefore, this study aims to delineate the demographic and clinical characteristics of asymptomatic or paucisymptomatic healthcare personnel at the General Hospital of Mexico "Dr Eduardo Liceaga" to create a better understanding of the evaluation of asymptomatic infections. At the time of completion of this study (26 May 2020), epidemiological data in Mexico reported 97,942 cumulative confirmed cases in the country and 20,235 cumulative confirmed cases in Mexico City?

\section{Materials and Methods}

Given the previous history and the window of opportunity that exists at the General Hospital of Mexico, as a COVID-19 center, a follow-up of asymptomatic or paucisymptomatic health personnel, who underwent a screening test, was carried out at the outpatient area of the otorhinolaryngology service. Epidemiologists and otolaryngologists performed this follow-up with the intention of screening the entire working population of the hospital. Samples obtained from nasal and oropharyngeal swabs were collected and processed by RT-PCR for SARS-COV2 detection, and the results were obtained 48-72 $\mathrm{h}$ after the study.

Samples of pharyngeal and nasopharyngeal exudates were received at the Genomic Medicine Unit, which were handled only by trained personnel in a type II biosafety cabinet (BCS-2) and wearing full PPE. The following commercial kits were used for RNA extraction: QIAmp Viral RNA Mini kit; QIAgen ${ }^{\circledR} /$ PureLink Viral RNA/DNA Mini kit; Thermofisher ${ }^{\circledR}$. Procedure began by taking an aliquot of the sample (140-300 uL, according to kit specifications) and placing it in a $1.5 \mathrm{~mL}$ tube with buffer solution for the washing and elution steps. For viral detection, RT-PCR was performed using SARS-CoV-2 genome-specific oligonucleotide and probe systems. The SARS-CoV-2 positivity result was given based on the amplification of the viral genes and the reference gene with $\mathrm{Cq}$ (cycle threshold) values below 40 .

Before the study, a form was completed with personal data and authorization was requested to answer a survey on associated symptoms and olfactory alterations. Standardized objective olfactory tests were not chosen for those patients who manifested such symptoms, because, in the current pandemic context, contamination of the examination material during the process of inhalation and exhalation of the patient during olfaction could not be ruled out. Follow-up was continued at 1 and 2 weeks electronically, the responses being voluntary.

In the period between May 11 and May 26, 2020, 496 tests were carried out on the staff described above, of which 376 agreed to answer our survey. These were randomly selected considering the first 40 people who presented themselves for sampling. The 376 respondents were contacted on a second occasion by e-mail and a second form with extended questions and developments was completed. Finally, the data were correlated with the positive results for SARS-CoV-2 given by the epidemiology service.

\section{Results}

Four hundred and forty-nine surveys were completed, of which 73 were excluded due to technical errors (e.g., two marked options). The following data were obtained:

Age: 21-63 years with a mean of 39.4 years (Table 1 and Fig. 1). The current hospital functions of the studied staff are described in table 1. Seventy-seven percent reported contact with patients with coronavirus infection; $32 \%$ reported exposure of $<8 \mathrm{~h} /$ week, $24 \%$ between 8 and $16 \mathrm{~h} /$ week, and $20 \%$ more than $16 \mathrm{~h}$ of exposure per week (Table 2).

Sixty-eight percent reported no comorbidities; the most frequent comorbidity was obesity with $13.8 \%$ followed by asthma with $8 \%$, and type 2 diabetes mellitus with $1 \%$ (Table 1). Symptomatology in the 14 days before the test was queried and the most common symptom was headache (34\%), followed by nasal obstruction (25\%); odynophagia in third place (22\%); and $25.7 \%$ reported no symptoms (Table 2). A targeted questioning of odor perception disturbances on the date of sampling yielded $16.1 \%$ positive results.

Among the staff surveyed, 17 (4.5\%) had a positive RT-PCR test result for SARS-CoV-2. Eleven of these 


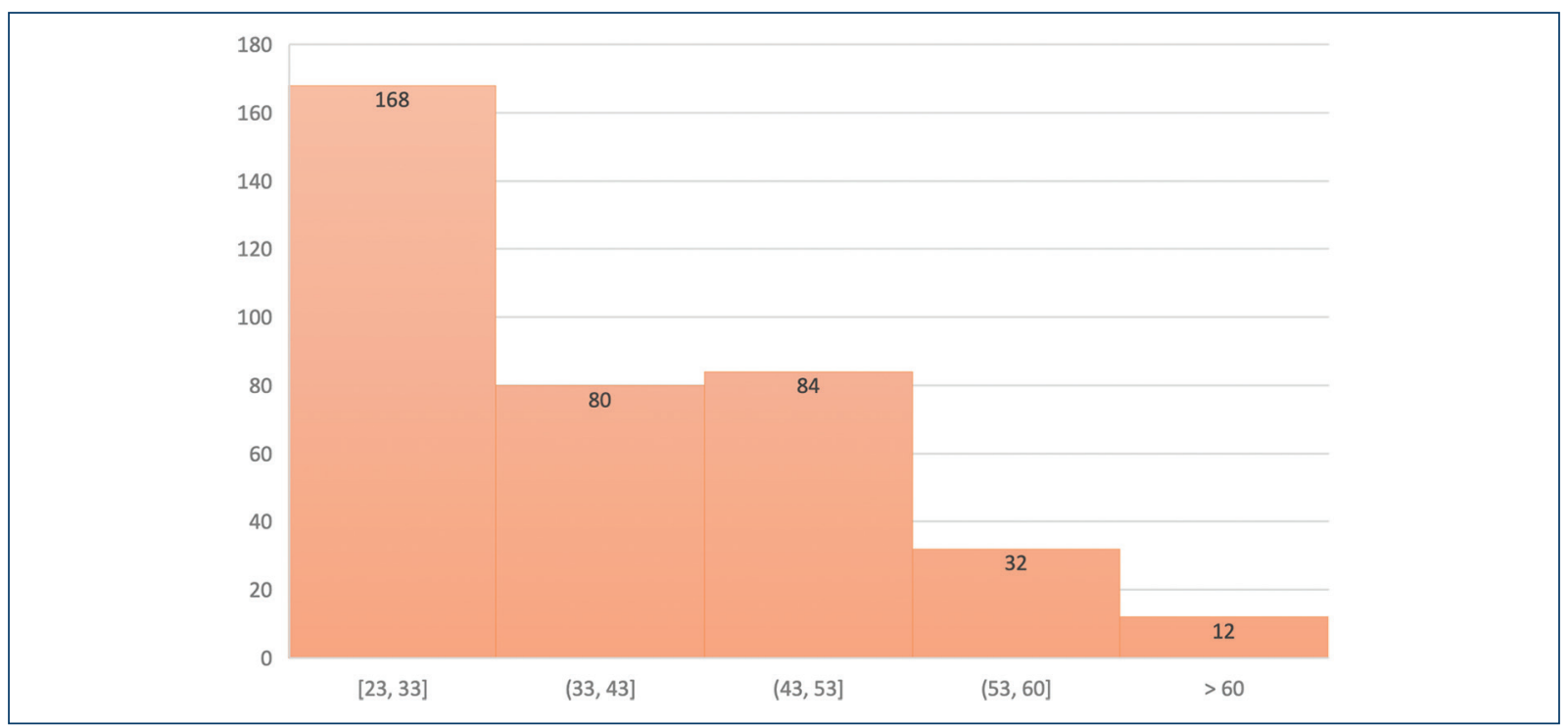

Figure 1. Age distribution.

Table 1. Demographic characteristics of the study population

\begin{tabular}{|c|c|c|}
\hline Variable & & \\
\hline \multirow[t]{2}{*}{ Age (years) } & \multicolumn{2}{|c|}{$42 \pm 21$} \\
\hline & Positive for SARS-CoV-2 (RT-PCR) & Negative for SARS-CoV-2 (RT-PCR) \\
\hline RT-PCR result for SARS-CoV-2 & $17(4.5 \%)$ & $359(95.5 \%)$ \\
\hline $\begin{array}{l}\text { Sex } \\
\text { Males (n 146) } \\
\text { Females (n 230) }\end{array}$ & $\begin{array}{c}7(1.8 \%) \\
10(2.6 \%)\end{array}$ & $\begin{array}{l}139(36.9 \%) \\
220(58.5 \%)\end{array}$ \\
\hline $\begin{array}{l}\text { Current functions within the General Hospital of Mexico } \\
\text { Residents (n 53) } \\
\text { Nurse (n 75) } \\
\text { Laboratory/radiology technician (n 38) } \\
\text { Medical staff (n 60) } \\
\text { Administrative staff (n 56) } \\
\text { Cleaners/Stretcher-bearers (n 19) } \\
\text { Area managers/Social work (n 41) } \\
\text { Other (lawyers, psychologists, nutritionists, cooks) (n 34) }\end{array}$ & $\begin{array}{c}2(0.5 \%) \\
4(1 \%) \\
1(0.25 \%) \\
4(1 \%) \\
4(1 \%) \\
1(0.25 \%) \\
1(0.25 \%) \\
0(0 \%)\end{array}$ & $\begin{array}{c}51(13.5 \%) \\
71(18.8 \%) \\
37(9.8 \%) \\
56(14.8 \%) \\
51(13.5 \%) \\
18(4.7 \%) \\
40(10.6 \%) \\
34(9 \%)\end{array}$ \\
\hline $\begin{array}{l}\text { Comorbidities } \\
\text { Asthma (n 30) } \\
\text { Obesity (n 52) } \\
\text { DM2 (n 4) } \\
\text { HIV (n 1) } \\
\text { Systemic arterial hypertension (n 1) } \\
\text { Other (hypotension, hypothyroidism, henoch-schönlein } \\
\text { purpura, dyslipidemia, overweight, allergies) (n 31) } \\
\text { No comorbidities (n 258) }\end{array}$ & $\begin{array}{c}1(0.25 \%) \\
1(0.25 \%) \\
0(0 \%) \\
0(0 \%) \\
0(0 \%) \\
0(0 \%) \\
15(3.9 \%)\end{array}$ & $\begin{array}{c}29(7.7 \%) \\
51(13.2 \%) \\
4(1 \%) \\
1(0.25 \%) \\
1(0.25 \%) \\
30(7.9 \%) \\
243(64.6 \%)\end{array}$ \\
\hline
\end{tabular}

(64\%) reported being asymptomatic. Among symptomatic patients, the most common symptom was again headache $(38 \%)$, followed by cough $(23 \%)$; three patients $(19 \%)$ reported altered odor perception on the date of sampling. This study did not have data on specific exposure of infected personnel, so it is unknown whether the infection originated inside or outside the hospital area. It is suggested that these data 
Table 2. Symptomatology in the 14 days before sampling//time of in-hospital exposure to SARS-CoV-2 positive patients

\begin{tabular}{|l|c|c|}
\hline Variable & \multicolumn{2}{|c|}{ Result } \\
\hline RT-PCR result for SARS-CoV-2 & Positive for SARS-CoV-2 (RT-PCR) & Negative for SARS-CoV-2 (RT-PCR) \\
\hline Symptomatology of the study population & & $121(32 \%)$ \\
Headache (n 128) & $7(1.8 \%)$ & $94(25 \%)$ \\
Nasal Obstruction (n 94) & $0(0 \%)$ & $83(22 \%)$ \\
Odynophagia (n 83) & $0(0 \%)$ & $0(0 \%)$ \\
Cough (n 4) & $4(1 \%)$ & $57(15 \%)$ \\
Altered sense of smell (n 60) & $3(0.8 \%)$ & $16(4.25 \%)$ \\
Other (Rhinorrhea, dysgeusia) (n 16) & $0(0 \%)$ & $86(22.8 \%)$ \\
\hline Asymptomatic (n 95) & $11(2.9 \%)$ & $115(30.5 \%)$ \\
\hline Hours of exposure with SARS-CoV-2 positive patients & & $87(23 \%)$ \\
\hline < $\mathrm{h} /$ week (n 121) & $6(1.6 \%)$ & $74(19.6 \%)$ \\
Between 8 and 16 h/week (n 91) & $4(1 \%)$ & $83(22 \%)$ \\
More than 16 h/week (n 78) & $4(1 \%)$ & $3(0.8 \%)$ \\
\hline No exposure (n 86) & $36 \%)$
\end{tabular}

be obtained for subsequent studies to be able to evaluate the effectiveness of the protection and distancing measures taken by health personnel in the work area.

\section{Discussion}

Interventions during this pandemic such as intensive contact tracing, isolation, and quarantine can effectively reduce the spread of COVID-19. Current recommendations for protective measures in our country such as hand hygiene, use of personal protective equipment according to contact areas, sterilization/disinfection of medical equipment, and cleanliness of facilities contribute to reducing the risk of infection ${ }^{8,9}$. There is evidence that human coronaviruses can be effectively inactivated within $1 \mathrm{~min}$ by using surface disinfection procedures with $62-71 \%$ ethanol, $0.5 \%$ hydrogen peroxide, or $0.1 \%$ sodium hypochlorite ${ }^{10}$. Identifying the causative pathogens of viral respiratory tract infections is important for selecting appropriate treatment, controlling the pandemic, and reducing the economic impact of COVID-19. However, the response to this situation in our country, as well as in some others, has been largely limited by the availability of the diagnostic test ${ }^{11}$.

Healthcare workers, and especially those involved in primary care of patients in COVID-19 areas, should be part of an ongoing and effective screening to help identify symptomatic or paucisymptomatic positive cases. The WHO currently recommends continued control interventions to reduce the overall risk of transmission of acute respiratory infections, including avoidance of close contact with people with acute respiratory infections and hand washing after direct contact with sick people or their environment ${ }^{8}$. In addition, people with symptoms of acute respiratory infection should practice social isolation, coughing, and sneezing etiquette, which consists of keeping social distancing, covering their mouths with tissues or clothing, and frequent hand washing. In a hospital setting, within health-care facilities, infection prevention, and control practices should be improved and standardized, especially in emergency departments ${ }^{10}$.

The results obtained in this study on the associated symptoms, particularly neurological symptoms such as headache and olfactory alterations; validate the findings in recent literature on the neurotropism that exists between SARS-CoV-2 and the cells of the nasal epithelium. In fact, it has been shown that human coronaviruses do not always limit their infection to the respiratory tract and can invade the central and peripheral nervous system ${ }^{12}$. However, in this study, as it is a screening of asymptomatic or paucisymptomatic health personnel, a lower incidence and intensity of this type of alterations is to be expected, without ignoring symptoms that appeared in the uninfected population, probably related to new health practices, such as the use of facial masks (nasal obstruction) and the level of stress (headache).

All clinicians should be aware that the presentation of symptoms extends far beyond the respiratory and sensory dimensions, involving psychosensory and neurological areas ${ }^{13}$. Knowledge of these dimensions and their clinical assessment could attract research interest in the neurobiological substrates involved in COVID-19 disease ${ }^{12}$, leading to a new approach to clinical screening, specific enough to detect potential infections, and 
to better target treatments at each stage of infection. To date, RT-PCR test is used for institutional screening and is a valuable tool for population control of this infection, but it has important limitations. Specificity is close to $100 \%$, sensitivity varies depending on the type of sample (sputum $89 \%$, nasal swab $73 \%$, and oropharyngeal swab $60 \%$ ), and variables related to correct sample collection and processing directly increase or decrease these figures ${ }^{14,15}$.

The work by the General Hospital of Mexico in identifying and isolating infected healthcare workers using the PCR test (RT-PCR) has been a particularly effective control measure for containing transmission between patients and staff. However, authorities must continue to monitor the situation, as the more we know about this new virus and its associated outbreaks, the better we will be able to respond thereto.

\section{Conclusions}

In the context of the current health emergency, it is vital to identify and isolate asymptomatic carriers and staff with mild symptomatology to contain outbreaks, in this case within the hospital area. During major outbreaks, the demand for healthcare workers grows even as the extreme pressures they face lead to a decrease in availability.

Screening as a detection tool for healthcare workers is necessary. However, it is not perfect and needs to be complemented by adequate use and knowledge of health and safety measures, personal protective equipment, and social distancing.

Further research in infected patients is also required to determine additional symptoms outside the classic triad of fever, cough, and shortness of breath, such as anosmia and dysgeusia, which although not specific for this disease, may represent a clinical screening tool. It may also guide diagnostic testing of paucisymptomatic individuals or request self-isolation in a safer way even in the absence of confirmatory testing.

\section{Funding}

No public or private funding was received for this manuscript. Demographic and clinical characteristics in asymptomatic health-care personnel with positive test for SARS-CoV-2, General Hospital of Mexico "Dr. Eduardo Liceaga."

\section{Conflicts of interest}

The authors declare that they have no conflict of interest.

\section{Ethical disclosures}

Protection of human and animal subjects. The authors declare that no experiments were performed on humans or animals for this study.

Confidentiality of data. The authors declare that they have followed the protocols of their work center on the publication of patient data.

Right to privacy and informed consent. The authors have obtained the written informed consent of the patients or subjects mentioned in the article. The corresponding author is in possession of this document.

\section{References}

1. Rahimi F, Abadi AT. Practical strategies against the novel coronavirus and COVID-19-the imminent global threat. Arch Med Res. 2020;51:280-1.

2. Huang $\mathrm{C}$, Wang $\mathrm{Y}$, Li X, Ren L, Zhao J, Hu Y, et al. Clinical features of patients infected with 2019 novel coronavirus in Wuhan, China. Lancet. 2020;395:497-506.

3. Li H, Liu SM, Yu XH, Tang SL, Tang CK. Coronavirus disease 2019 (COVID-19): current status and future perspectives. Int J Antimicrob Agents. 2020:55:105951.

4. Lovato A, de Filippis C, Marioni G. Upper airway symptoms in coronavirus disease 2019 (COVID-19). Am J Otolaryngol Head Neck Med Surg. 2020;2019:102474.

5. Hu Z, Song C, Xu C, Jin G, Chen Y, Xu X, et al. Clinical characteristics of 24 asymptomatic infections with COVID-19 screened among close contacts in Nanjing, China. Sci China Life Sci. 2020;63:706-11.

6. Cardona GC, Páiaro LD, Marzola ID, Villegas Y, Salazar LR. Neurotropism of SARS-CoV 2: mechanisms and manifestations. J Neurol Sci. 2020;412:116824.

7. Gobierno de México. COVID-19 Tablero México-CONACYT; 2020. Available from: https://www.coronavirus.gob.mx/datos/\#DOView. [Last accessed on 2020 Sep 01].

8. Comite COE Construccion, Organización Mundial de la Salud, ADELCA ARROYO and ARROYO, ACEROCENTER NYKSA, Con R, Sanitarias A Acciones PDE, et al. Protocolo de Investigación de los Primeros Casos y sus Contactos Directos (FFX) de la Enfermedad por Coronavirus 2019 (COVID-19). MINSALMINSAL. Cuarentena en Tiempos COVID-19 MINSAL; 2020. p. 1-56. Available from: https://www.who.int/emergencies/diseases/novel-coronavirus-2019/technical-guidance/early.

9. Gobierno de México. Lineamiento Técnico de uso y Manejo del Equipo de Protección Personal ante la Pandemia por COVID-19. México: Gobierno de México; 2020.

10. Lai CC, Shih TP, Ko WC, Tang HJ, Hsueh PR. Severe acute respiratory syndrome coronavirus 2 (SARS-CoV-2) and coronavirus disease-2019 (COVID-19): the epidemic and the challenges. Int J Antimicrob Agents. 2020;55:105924

11. Tu YP, Jennings R, Hart B, Cangelosi GA, Wood RC, Wehber K, et al. Swabs collected by patients or health care workers for SARS-CoV-2 testing. N Engl J Med. 2020;382:494-6.

12. Pallanti S. Importance of SARs-Cov-2 anosmia: from phenomenology to neurobiology. Compr Psychiatry. 2020;100:152184.

13. Suárez V, Quezada MS, Ruiz SO, De Jesús ER. Epidemiología de COVID-19 en México: del 27 febrero al 30 de abril de 2020. Rev Clín Española. 2020;2020:1-7.

14. Díaz-jiménez IV. Interpretación de las pruebas diagnósticas del virus SARS-Cov-2 virus. Acta Pediatr Mex. 2020;41:51-7.

15. Yang Y, Yang M, Shen C, Wang F, Yuan J, Li J, et al. Evaluating the Accuracy of Different Respiratory Specimens in the Laboratory Diagnosis and Monitoring the Viral Shedding of 2019-nCoV Infections. medRxiv; 2020. 